\title{
Glycogen storage disease due to muscle beta-enolase deficiency
}

INSERM

\section{Source}

INSERM. (1999). Orphanet: an online rare disease and orphan drug data base. Glycogen storage disease due to muscle beta-enolase deficiency. ORPHA:99849

Muscle beta-enolase deficiency is a glycolysis disorder reported in one patient to date and characterized clinically by exercise intolerance and myalgia due to severe enolase deficiency in muscle. 